\title{
Evidence Based Medicine in Physical Medicine and Rehabilitation
}

Helmut Kern (1,2), Stefan Loefler (2), Veronika Fialka-Moser (3,4), Tatjana Paternostro-Sluga $(3,4)$, Richard Crevenna $(3,4)$, Samantha Burggraf (2), Hannah Fruhmann (2), Christian Hofer (2), Claudia Burmester (1), Benjamin Süsoy (2), EvaMaria Strasser (10,11), Markus Praschak (11), Wolfgang Grestenberger (6), Friedrich Hartl (7), Gerold Ebenbichler (3,5), Günther Wiesinger (3), Thomas Bochdansky (8), Christian Wiederer (9), Michael Quittan $(4,10,11)$

(1) Dept. of Physical Medicine and Rehabilitation, Wilhelminenspital, Vienna, Austria; (2) Ludwig Boltzmann Institute of Electrical Stimulation and Physical Rehabilitation, Vienna, Austria; (3) University Clinic of Physical Medicine, Medical University of Vienna, Austria; (4) Austrian Society for Physical Medicine \& Rehabilitation (ÖGPMR); (5) Berufsverband der Österreichischen Fachärzte für Physikal. Medizin und Rehabilitation (BÖPMR), Vienna, Austria; (6) Fachgruppe Physikal. Medizin, Wiener Ärztekammer, Austria (7) Bundesfachgruppe Physikal. Medizin, Österreichische Ärztekammer, Austria; (8) Reha-Klinik Montafon, Schruns, Austria; (9) Kurhaus Bad Gleichenberg, Austria; (10) Dept. of Physical Medicine and Rehabilitation, Kaiser Franz Joseph Hospital, Vienna, Austria; (11) Karl Landsteiner Institut für Remobilisation und funktionale Gesundheit, Vienna, Austria;

\begin{abstract}
Evidence Based Medicine in Physical Medicine and Rehabilitation

In the last twenty years the term "Evidence Based Medicine (EBM)" has spread into all areas of medicine and is often used for decision-making in the medical and public health sector. It is also used to verify the significance and/or the effectiveness of different therapies.

The definition of EBM is to use the physician's individual expertise, the patient's needs and the best external evidence for each individual patient. Today, however, the term EBM is often wrongly used as a synonym for best "external evidence". This leads not only to a misuse of evidence based medicine but suggests a fundamental misunderstanding of the model which was created by Gordon Guyatt, David Sackett and Archibald Cochrane.

This problem becomes even greater the more social insurance institutions, public healthcare providers and politicians use external evidence alone as a main guideline for financing therapies in physical medicine and general rehabilitation without taking into account the physician's expertise and the patient's needs. The wrong interpretation of EBM can lead to the following problems: well established clinical therapies are either questioned or not granted and are therefore withheld from patients (for example physical pain management).

Absence of evidence for individual therapy methods does not prove their ineffectiveness!

In this short statement the significance of EBM in physical medicine and general rehabilitation will be analysed and discussed.
\end{abstract}

Key Words: EBM, evidence based medicine, physical medicine, physiotherapy, rehabilitation 


\section{Introduction - Definition and meaning of EBM}

In the past 20 years the term "Evidence Based Medicine" (EBM) has spread into all domains of medicine and is often used for medical and health care decisions.

According to the pioneers of EBM Gordon Guyatt and David Sackett, co-founders of the first international EBM working group ("evidence based medicine working group"), EBM is ,the conscientious, explicit, and judicious use of current best evidence in making decisions about the care of individual patients." The practice of evidence-based medicine means integrating individual clinical expertise and patient values with the best available external evidence from systematic research $[9,23]$.

„By best available external clinical evidence we mean clinically relevant research, often from the basic sciences of medicine, but especially from patient centred clinical research ..."[23].

Sackett demonstrated in BMJ 1996 how these three areas of EBM form the valuation of therapy methods and how they have to be evaluated for each individual patient. (Fig.1.)

\section{General and International Criticism relating to EBM}

Nowadays many protagonists both in medicine and health care policy use and discuss the term EBM and it is increasingly used for making decisions about medicine and health care. Today a particular therapy or treatment is often only considered to be correct if it bears the endorsement EBM, regardless whether all aspects of EBM have been taken into account [28].

EBM is discussed internationally because the term EBM is often wrongly used as a synonym for the „external scientific evidence“ without taking the clinical expertise and patient values into consideration. Another point of criticism is that EBM is understood as medicine which is based on results of studies which have to fulfil certain methodological requirements such as double-blind, randomised, controlled trials (RCTs). Studies of this kind are mainly used in the pharmacological sector for the approval of new pharmaceuticals and are not applicable for all medical treatments or therapies. Such double-blind trials are inappropriate for many questions in physical medicine.

To reduce the scientific argumentation in medicine solely to the statistical results of RCTs and meta analyses restricts science and leads to a loss of

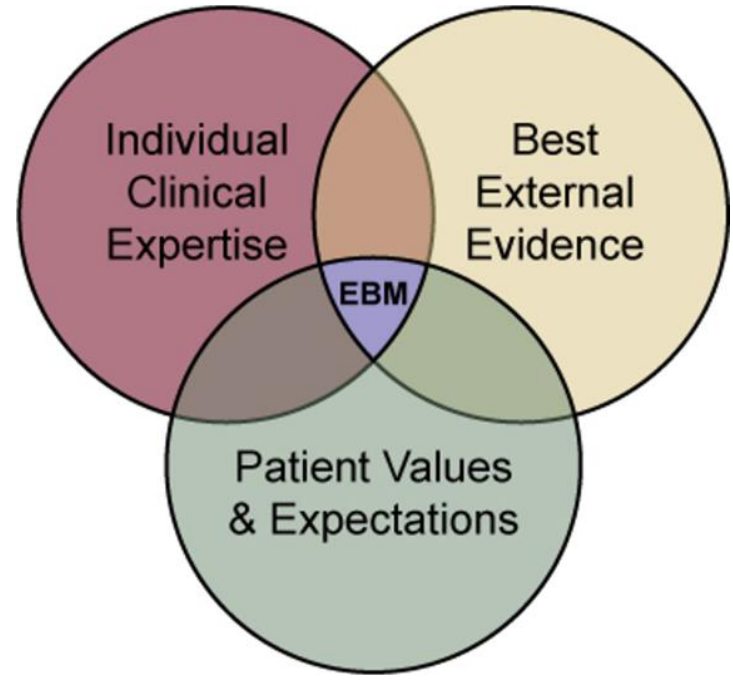

Fig.1 Graphical illustration of the EBM Triad which represents the three areas of EBM

knowledge. Nevertheless, this methodological approach to scientific results is defended almost ideologically [28].

Sackett's view is that RCTs and scientific reviews of RCTs provide reliable proof that therapies are more beneficial than harmful. However, he also points out that some questions about therapies do not require RCTs [23].

„Evidence based medicine is not restricted to randomised trials and meta-analyses“" [23].

Some who are not familiar with EBM only evaluate the

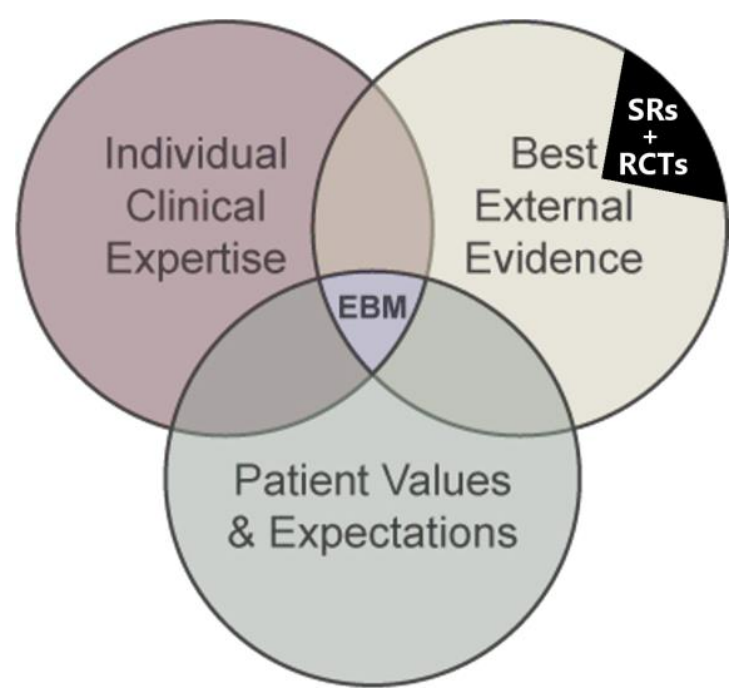

Fig.2. Adapted illustration of the EBM Triad with $E B M$ reduced to a minor part of external evidence 


\section{Evidence Based Medicine in Physical Medicine and Rehabilitation}

European Journal Translational Myology - Basic Applied Myology 2013; 23 (4): 217-220

"external evidence" (Fig.2.).

However this is completely contrary to the concept of the "fathers" of EBM who consider all three areas to be equally important.

The missunderstanding in the interpretation of EBM becomes obvious when considering the illustration of the EBM Triad of the Florida State University on the Cochrane homepage and differentiating the details of the three areas. (Abb.3)

External evidence includes all types of studies. Therefore it is problematic to reduce the external evidence only to level 1 and 2 studies because a lot of knowledge is not taken into account.

Internationally this condition is criticized consistently $[20,30]$, as can best be shown by the graphic demonstration of the American Chiropractors Association. (Fig.3. table top right).

Other types of studies should also be cited and assessed. In particular literature about fundamental scientific research which is listed in international peer reviewed journals with impact points should be taken into consideration.

However this would require a greater effort during the assessment of external evidence, than if the search for literature were limited to RCTs and meta analyses in order to propagate results of more superficial work as "evidence" or "no evidence".

A restriction of the assessment of external evidence to RCTs und meta analyses is misleading and unscientific.

Often the search for literature is limited to a few electronic databases such as Pubmed, Medline, Cochrane Homepage, Embase etc. and to a time frame of the last 15-20 years. Older literature or literature which can only be found in books, printed journals or cannot be found electronically is often ignored.

The statistical significance level should also be taken into account. The fact that it is possible to get a statistically significant result with a large sample size which can be clinically irrelevant should be taken into consideration [27]. Therefore it is absolutely necessary to question the physiological reasonableness and clinical relevance of individual studies or reviews.

Rating agencies such as the Cochrane Centre or Health Technology Agencies claim to get over this problem through statistical analyses and filter out knowledge which the "normal" physician is not capable of. However proof for the effectivity of this procedure in terms of improving the physical condition of the population has not yet been confirmed [28]. If appropriate therapies are determined only that way, the doctor's work would be devalued and reduced ad absurdum.

If you look at RCTs and meta analyses closely following problems can be seen:

El Dib reported that in $96 \%$ of 1024 Cochrane reviews no exact statement is made [6].

Epstein demonstrated in BMJ 2007 that in 124 meta analyses about antihypertensive therapies only 55\% show positive results but a positive conclusion is made in $92 \%$ of the studies. This seems to depend on the industrial sponsors of the studies [7].

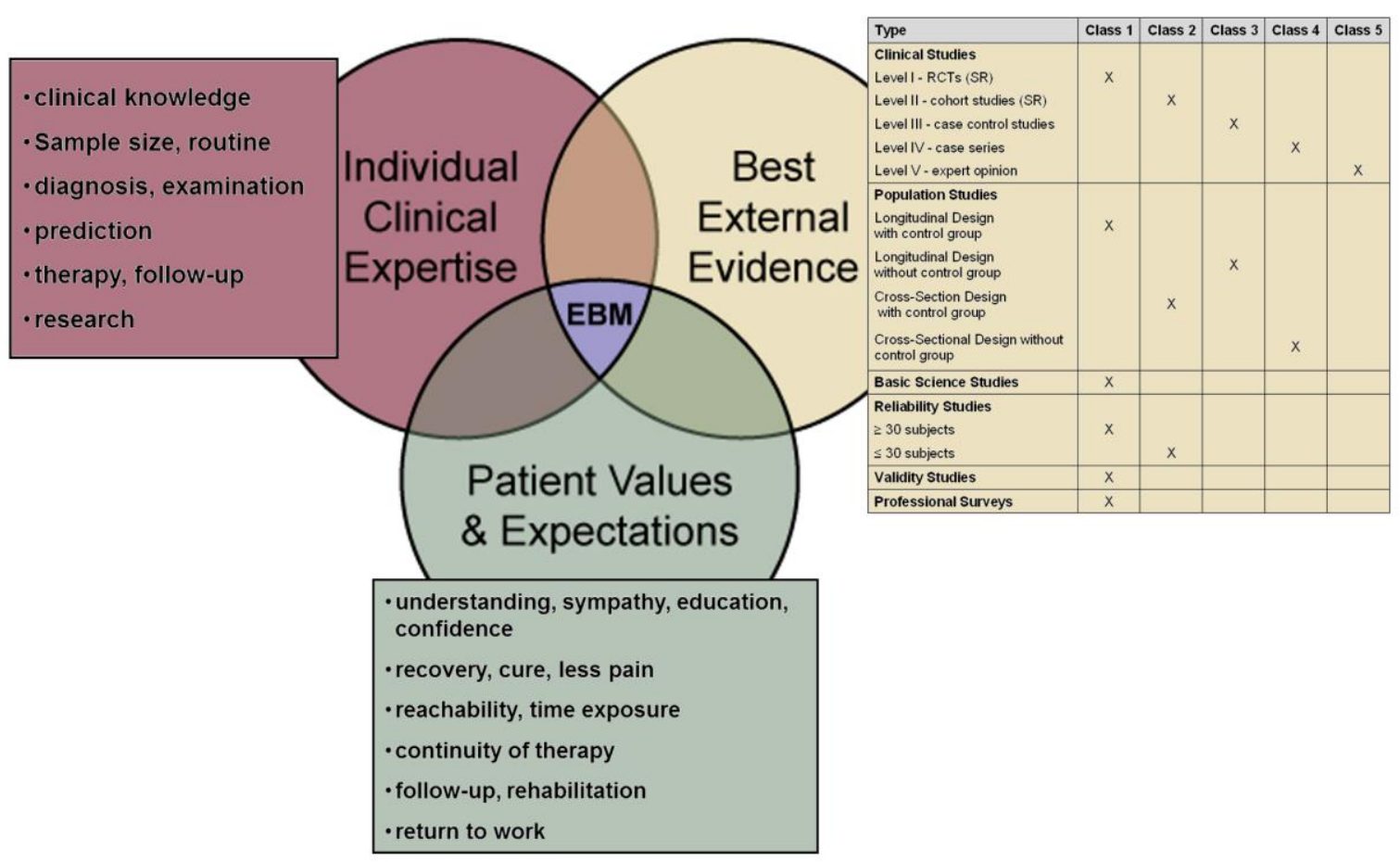

Fig.3. Detailed illustration of all 3 areas of the EBM-Triad with a table of important types of studies for "best external evidence". 


\section{Evidence Based Medicine in Physical Medicine and Rehabilitation}

European Journal Translational Myology - Basic Applied Myology 2013; 23 (4): 217-220

Apart from this, it becomes evident that negative clinical study results are, for a variety of reasons, published much less frequently [25].

„Good doctors use both individual clinical expertise and the best available external evidence, and neither alone is enough. Without clinical expertise, practice risks becoming tyrannised by evidence, for even excellent external evidence may be inapplicable to or inappropriate for an individual patient"“ [23].

\section{EBM - in Physical Rehabilitation Medicine}

The national committee of American Chiropraticians worked out a national guideline which indicates that not only RCTs and meta analyses should be used to assess external evidence, but also all other types of studies, in particular the results of scientific and clinical basic research [20].

Limiting assessment based on RCTs and meta analyses with level 1 or 2 per se must be seen just as critically as limiting the time frame of analyses for guidelines to the last few years. Especially in the domain of physical medicine and general rehabilitation many proven therapies such as massage, electrical therapy and ultrasound are documented in older studies published in books and are therefore not used in assessments [2,3,5,8,10-16,18,19,21,22,26].

The biological variability of the human being is the reason why, in the field of medicine, results even from high level studies can never describe the effect of an intervention as precisely as in mathematical or physical studies [28]. Wichert believes that the use of complex mathematical methods do not change anything in this biological variability [28].

Reasons for the limited number of RCTs and meta analyses in the medical field in comparison to drug studies are a combination of the variability of the methods, the applied parameters (e.g. stimulationparameters, patient collective, compliance, blinding) and the biological variability of human and environmental factors [26].

Another problem which complicates the carrying out of large scale studies in physical medicine is the lack of financial support in contrast to the support given to the development of pharmaceuticals because there are no companies which invest in this sector of medicine.

A further serious weakness in the present assessment of physical treatment methods is that studies which examine the combination of different therapies are not taken into consideration. Precisely these combination therapies are used in daily practice in patients' interests because they have proven themselves clinically to be effective and more beneficial [17,26]. RCTs in which solely monotherapies are analyzed, do not allow any reliable statements about the treatment with combination therapies and therefore lead to inconsistent conclusions.

Another reason for the absence of level 1 studies is that some of the physical treatments such as massage and electrical therapy do not allow pure placebo groups and double blind studies are often difficult or even impossible [17].

"Absence of evidence is not evidence of absence" [1]. The absence of external evidence for individual forms of therapies is not proof of their ineffectiveness. Nevertheless, many of those responsible draw the wrong conclusion [4,29].

This problem becomes even more relevant the more social insurance companies and politicians use the wrong interpretation of EBM as decision criterion for therapy guidelines and their economic evaluation.

It is unethical and unscientific if the physician's clinical experience and the patient's needs as well as the scientific basic research of physical therapies are ignored.

Because of the wrong interpretation of EBM well established clinical therapies (e.g. physical pain management) may be questioned, not approved and withheld from the patients.

Evaluative authorities (e.g. experts of the social insurance companies, Austrian example: „Sozialversicherungsträger (SV)“, Hauptverband der SV) should not make the mistake of assessing only the scientific "external evidence" without taking all parts of EBM into consideration as required by Gordon Guyatt and David Sackett.

In the end it is the doctor who evaluates the present best scientific literature for the individual patient's treatment [23].

\section{Acknowledgement}

Thanks to all researchers for their support.

\section{Corresponding Author}

Prim. Univ.-Prof. DDr. Helmut Kern, Institut für Physikalische Medizin und Rehabilitation, Wilhelminenspital, Montleartstraße 37, A-1160 Wien, Österreich e-mail: wil.pys.kern-forschung@ wienkav.at.

\section{Literature}

[1] Alderson P. Absence of evidence is not evidence f absence. BMJ. 2004;328(7438):476477.

[2] Boncompagni S, Kern H, Rossini K, Hofer C, Mayr W, Carraro U, et al. Structural differentiation of skeletal muscle fibers in the 


\section{Evidence Based Medicine in Physical Medicine and Rehabilitation}

European Journal Translational Myology - Basic Applied Myology 2013; 23 (4): 217-220

absence of innervation in humans. Proc Natl Acad Sci USA. 2007;104(49):19339-19344.

[3] Braddom RL. Handbook of Physical Medicine and Rehabilitation. Saunders; 2004.

[4] Brandstätter S. Rückenleiden: Gesund werden. Gesund bleiben 2. Holzhausen Verlag $\mathrm{GmbH}$; 2009.

[5] Bringezu G, Schreiner O. Die Therapieform manuelle Lymphdrainage: ein aktuelles Lehrbuch einer erfolgreichen Behandlungsmethode. 3. Aufl. Ebert; 1997.

[6] El Dib RP, Atallah AN, Andriolo RB. Mapping the Cochrane evidence for decision making in health care. J Eval Clin Pract. 2007;13(4):689692.

[7] Epstein RA. Influence of pharmaceutical funding on the conclusions of meta-analyses. BMJ. 2007;335(7631):1167.

[8] Gutmann E. The denervated muscle. Pub. House of the Czechoslovak Academy of Sciences; 1962

[9] Guyatt G CJ. Evidence-based medicine: A new approach to teaching the practice of medicine. JAMA. 1992;268(17):2420-2425.

[10] Jantsch H, Schuhfried F. Niederfrequente Ströme zur Diagnostik und Therapie. 2. Aufl. Maudrich; 1981.

[11] Kern H. Funktionelle Elektrostimulation paraplegischer Patienten. Österr Z Phys Med. 1995;5(1 Suppl):1-79.

[12] Kern H, Boncompagni S, Rossini K, Mayr W, Fanò G, Zanin ME, et al. Long-term denervation in humans causes degeneration of both contractile and excitation-contraction coupling apparatus, which is reversible by functional electrical stimulation (FES): a role for myofiber regeneration? J Neuropathol Exp Neurol. 2004;63(9):919-931.

[13] Kern H, Carraro U, Adami N, Biral D, Hofer C, Forstner $\mathrm{C}$, et al. Home-based functional electrical stimulation rescues permanently denervated muscles in paraplegic patients with complete lower motor neuron lesion. Neurorehabil Neural Repair. 2010;24(8):709721.

[14] Kovács R. Electrotherapy and Light Therapy: With Essentials of Hydrotherapy and Mechanotherapy. 6. Aufl. Lea \& Febiger; 1949.

[15] Kowarschik J. Die Diathermie. 7. Aufl. Springer Verlag; 1930.

[16] Kowarschik J. Physikalische Therapie. 2. Aufl. Springer; 1957.
[17] Lange U, Berg W, Engel MJ, Fetaj S, Lichti G, Reuss-Borst M, et al. Evidenz zur Physikalischen Medizin in der Rheumatologie. Aktuelle Rheumatologie. 2009;34(05):299-302.

[18] Licht S. Stroke and its rehabilitation. E. Licht; 1975.

[19] Mennell JB. Physical Treatment by Movement, Manipulation and Massage: With 288 Illustrations, Some in Colour. 5. Aufl. Churchill; 1945.

[20] National Guideline Clearinghouse (NGC). Practicing Chiropractors' Committee on Radiology Protocols (PCCRP) for biomechanical assessment of spinal subluxation in chiropractic clinicalpractice. Available at: http://www.guideline.gov/content.aspx?id=1457 6 [Accessed 20th Aug. 2013]

[21] Rogoff JB, Licht SH. Manipulation, traction, and massage. 2. Aufl. Williams \& Wilkins; 1980.

[22] Rusk HA. Rehabilitation Medicine. 4. Aufl. C. V. Mosby; 1977.

[23] Sackett DL, Rosenberg WMC, Gray JAM, Haynes RB, Richardson WS. Evidence based medicine: what it is and what it isn't. BMJ. 1996. 312(7023):71-72.

[24] The Evidence-based Medicine Triad. Available at: http://www.cochrane.org/about-us/evidencebased-health-care [Accessed 11th Nov. 2013]

[25] Turner EH, Matthews AM, Linardatos E, Tell RA, Rosenthal R. Selective Publication of Antidepressant Trials and Its Influence on Apparent Efficacy. New England Journal of Medicine. 2008;358(3):252-260.

[26] Watson T. Electrotherapy: Evidence-based Practice. 12. Aufl. Churchill Livingstone; 2008.

[27] Weßling H. Theorie der klinischen Evidenz: Versuch einer Kritik der Evidenzbasierten Medizin. LIT Verlag Münster. 2011.

[28] Wichert, Peter. Evidenzbasierte Medizin (EbM): Begriff entideologisieren. Dtsch Arztebl. 3. Juni 2005;102(22):A1569-570.

[29] Wildbacher Ingrid, Brandstätter Silvia, Kruzic Nives, Gerner Gabriele, Kiesl Ute. Österreichischer Muster-Leistungskatalog Physikalische Medizin - empirische Grundlagen zur Wirksamkeit der Inhalte. GMS Health Technology Assessment. 2013;9:1-14.

[30] Zuiderent-Jerak T, Forland F, Macbeth F. Guidelines should reflect all knowledge, not just clinical trials. BMJ. 2012;345:e6702. 